\title{
Katherine Busse, Framing Fan Fiction
}

\begin{abstract}
Alison Morrow
Busse, Katherine, Framing Fan Fiction: Literary and Social Practices in Fan Fiction Communities (lowa City: University of lowa Press, 2017).

Kirk and Spock walk into a bar, take one look at each other over their drinks, and fall in love. While this scenario may never appear in a television episode or on the movie theater's big screen, variations upon it fill corners of the internet where fans form communities to share, argue over, and ultimately, write original stories set in their favorite worlds and utilizing their favorite characters. Kristina Busse's Framing Fan Fiction: Literary and Social Practices in Fan Fiction Communities compiles her scholarship on fan fiction and the community of writers who contribute. In seven previously published essays and three new ones, she defines fan fiction stories as cultural artifacts of the digital era which must be studied within the cultural context of the communities from whence they emerged, as opposed to strict literary analysis that ignores the community.
\end{abstract}

Busse situates fan fiction through the lens of authorship debates of the twentieth century: scholars alternately called the author god, dead, or something in between. Fan fiction, Busse suggests, returns the author to a place of prominence, and empowers the mostly female readers to find themselves within the stories, thus turning them into authors as well by enlisting them in a communal project. These new authors, however, operate in a "gift economy" rather than a capitalistic one, and usually, but not always, claim to own nothing personally. Busse posits that they share their stories, and thus, authorship with the community of fans surrounding them. Through three thematic analyses, Busse explores the communities' use of the canonical texts for self-expression and self-exploration; the fraught negotiation of meaning and eventual convergence of the authors of the source material and a community that substantially transforms that source material; and the interplay of tensions and discord within the communities themselves.

Busse offers a brief history of fan studies, including tracing the academic themes that have moved in and out of fashion (ex. Constance Penley's psychoanalysis, Nicholas Abercrombie and Brian Longhurst's spectacle/performance paradigm, Rebecca Black's fan activism and pedagogy). She primarily builds on Henry Jenkins' work defining fans as active participants in a community and examining the points of intersection between the creators and the fans. She locates fan fiction as a product of fan communities with little agency. The mostly female writers engage in a type of double subversion of gender - first, as women who are typically blocked from engaged fandom and expected to be passive recipients of mostly masculine works, these women insert themselves and their ideas into the stories, actively performing fandom. Second, these stories explore gender and sexuality, often introducing gay relationships between canonically straight characters, or introducing new characters, which serve as avatars for the audience, as love interests for beloved characters. These writings legitimize (female) fan voices and present a femininity that is neither passive nor prudish. This subversion of traditional femininity, Busse implies, leads to tension with the (often male) creators, who sometimes see fan fiction as an infringement upon their ownership. The fan fiction communities have worked to create acceptable compromises between creators and fan fiction writers, most often using the argument that fan fiction authors "own nothing," although this philosophy has been challenged in the last decade (Busse 140). These compromises are most explored in Chapter Four "Affective Imagination," which examines media creators' depictions of fan fiction writers in mainstream works, and Chapter Five "May the Force Be With You," which analyzes fan fiction writers' negotiation of authority by accepting or rejecting otherwise canonical elements of popular stories.

As both an academic and an active participant in fan fiction, Busse delineates the appeal of fan fiction for the community members, defines the characteristics of fan fiction in the digital era, and straightforwardly explores the 
thorny ethical issues surrounding a community devoted to writing in worlds that they do not - and cannot - own. Because this book is based on Busse's own experiences within fandom, however, her perspective is necessarily limited. The book covers the popular fan fiction fandoms of the United States from the 1990s to present day, including works like Harry Potter, Star Trek, Supernatural, and Twilight, as well as exploring fan fiction about celebrities like members of famous boy bands. In doing so, Busse provides a framework for understanding this subset of fandom, but it is not clear if this framework can or should be extended to the fan fiction that does not fit this definition. Does it, for example, reach back to the fan fiction of tv's Beauty and the Beast, which developed from a community strong enough to successfully save their show from cancellation in 1989? Does slash fiction, which explores homosexual relationships between canonically straight characters, still act as feminist subversion when encountered in fan fiction stories about anime from Japan? For that matter, are fan fiction participants from other countries also primarily women, and should their writing also be seen primarily as women's writing? Do the same tensions arise between original creators and fan fiction communities when both creator and fans come from cultures with different concepts of creative ownership? What role does race play in membership within these communities of writers?

Another important question, what happens when non-professional writers post stories based on non-genre literature? Are these still considered fan fiction? Are these authors also fans? Or, from another perspective, when part of the definition of these communities and their creative products is that they operate on a gift currency important because this claim helps negate any legality issues - what happens when the fan community is based around a piece of work in the public domain, such as Pride and Prejudice, and fan fiction authors publish professionally, as in Marsha Altman's Road to Pemberley: An Anthology of New Pride and Prejudice Stories?

Busse offers a text that only a fan community member could write; she comprehensively defines what fan fiction is, at least for the most prominent fan fiction communities. She elucidates the challenges individuals within the online communities face, and how they react to those challenges. And she highlights the relationships between author, source text, audience, and derivative texts. Busse ends her volume by suggesting that fan fiction "thrives in the margins" of media and culture, and that "within fan culture, often the most derided genres showcase our id vortex; the most passionate debates reveal fault lines within the community and maybe culture at large" (218). Illuminating these issues, as Busse has done, allows academics to venture further into the emotional world, and potentially, gain further insight into the cultures we all inhabit to some extent. Busse's definition of fan fiction allows the astute reader to wonder about the missing voices - voices that Busse herself recognizes as missing. Those missing voices in fan fiction studies, Busse suggests, may be a reflection of the missing voices in society at large. She anticipates further research that includes those voices. Framing Fan Fiction acts as a foundational text for the emerging field of fan fiction studies within fandom studies. We look forward, now, to the developments that are building on Busse's insights.

\section{Cite this Essay}

Morrow, Alison. "Katherine Busse, Framing Fan Fiction." Rhizomes: Cultural Studies in Emerging Knowledge, no. 35, 2019, doi:10.20415/rhiz/035.r05

RHIZOMES ISSN 1555-9998 ^ 230 East Hall Bowling Green State University Bowling Green, OH 43403

Editors: Ellen Berry and Carol Siegel. Reviews editor: Craig J. Saper. Technical editor: Helen J Burgess 